\title{
A unique case of black choledocholithiasis: a video-based case review in the Pancreato-Biliary Division-Endoscopy Unit of National Liver Institute (NLI)
}

\author{
Omkolsoum Alhaddad ${ }^{1}$, Maha Elsabaawy ${ }^{1 *}$ (D), Olfat Hendy ${ }^{2}$, Ahmed Kamal ${ }^{1}$ and Helmy Elshazly ${ }^{1}$
}

\begin{abstract}
Background: Black gall stones are consistently described in relation to haem turnover and hemolytic disorders. Black gall stones are also a frequent presentation in cirrhotic patients, principally due to hemolysis-related hypersplenism.

Case presentation: Herein, we present a case of an average built 83-year-old lady who was suffering from biliarytype abdominal episodes of pain. Neither clinical nor laboratory evidence of overt biliary obstruction, cholangitis, or pancreatitis was detected. Sonographic examination revealed the presence of calcular gall bladder with many small stones, dilated common bile duct (CBD), and biliary radicles, along with homogenous average-sized liver, averagesized spleen with normal echogenicity and no focal lesions. Endoscopic retrograde cholangiography (ERC) was performed with wide papillotomy which was surprisingly followed by a drift of innumerable intensely black small stones.
\end{abstract}

Conclusion: In aged population, absence of the full-blown clinical syndrome in relation to complicated CBD stones should not exclude endoscopic intervention.

Keywords: Black stones, Choledocholithiasis, Cholelithiasis, Case report

\section{Background}

Gall stones are solid particles made of bile, cholesterol, and bilirubin. Unconjugated hyperbilirubinemia is the principal theme for the formation of pigment gall stones [1]. CBD stones can be associated with threatening sequelae that can present as an emergency [2]. On top of such sequelae is acute biliary pancreatitis by either impacted or spontaneously passed stones. Obstructive jaundice, recurrent ascending cholangitis, and secondary biliary cirrhosis are among the sequelae of CBD stones [3]. Acute biliary pancreatitis had been reported in about $33 \%$ to $50 \%$ of those with CBD stones [4] and can cause

\footnotetext{
*Correspondence: maha.ahmed@liver.menofia.edu.eg

'Department of Hepatology and Gastroenterology, National Liver Institute,

Menoufia University, Shebeen El-Koom 32511, Egypt

Full list of author information is available at the end of the article
}

mortality in about $6 \%$ to $9 \%$ of these people [5]. Moreover, mortality related to calcular cholangitis reaches around 24\% [6]. Therefore, detection and proper management of choledocholithiasis should be ultimately undertaken.

\section{Case presentation}

An 83-year-old lady presented to the pancreato-biliary clinic at National Liver Institute, Menoufia University, with a 4-month history of intermittent abdominal pains that lately become more intense and unremitting. She did not report any fever, jaundice, previous operations, or blood transfusion. She has long-standing controlled hypertension on mono anti-hypertensive therapy (Captopril $25 \mathrm{mg} /$ day) and no diabetes, no history of other chronic diseases or medications. On examination, she 
was neither febrile nor jaundiced but had a tender upper abdomen. Her recent sonographic examination revealed markedly dilated common bile duct (CBD) (11 $\mathrm{mm}$ ), mildly dilated intrahepatic biliary channels, and a gall bladder containing many small-sized calculi, with echogenic normal sized liver, and homogenous averagesized spleen with no focal lesions. Surprisingly, her immediate laboratory investigations did not show the expectedly raised inflammatory and cholestatic parameters (Table 1).

She had a normal leucocytic count, serum bilirubin, and liver and pancreatic enzymes as well (Table 1). Magnetic resonance cholangiography (MRC) was able to identify the dilated CBD, and biliary radicles; however, no evidence of choledocholithiasis was perceived (Fig. 1). Despite normal serum bilirubin levels and owing to the significant CBD dilatation, endoscopic retrograde cholangiopancreatography (ERCP) was decided.

After proper sedation and selective cannulation of the CBD; cholangiography confirmed the presence of markedly dilated CBD in addition to innumerable filling defects (Fig. 2a, b). Generous papillotomy was successfully undertaken to be immediately followed by a passage of a large number of small bizarre shaped intensely black

Table 1 Laboratory data of the case on presentation

\begin{tabular}{|c|c|c|}
\hline Variables & & Pre-ERCP \\
\hline \multirow[t]{3}{*}{$\mathrm{CBC}$} & $\mathrm{Hb}(\mathrm{g} / \mathrm{dL})$ & 10.3 \\
\hline & WBC $\left(10^{3} / \mu \mathrm{L}\right)$ & 5.9 \\
\hline & Platelets $\left(10^{3} / \mu \mathrm{L}\right)$ & 246 \\
\hline \multirow[t]{8}{*}{ Liver profile } & Albumin (g/dl) & 4.7 \\
\hline & Bilirubin (mg/dL) & 0.8 \\
\hline & PT (\%) & 100 \\
\hline & INR & 0.9 \\
\hline & AST (U/L) & 34 \\
\hline & ALT (U/L) & 32 \\
\hline & ALP (U/L) & 93 \\
\hline & GGT (U/L) & 34 \\
\hline \multirow[t]{4}{*}{ Renal profile } & Urea (mg/dL) & 31 \\
\hline & Creatinine $(\mathrm{mg} / \mathrm{dL})$ & 0.5 \\
\hline & Sodium (mmol/L) & 145 \\
\hline & Potassium (mmol/L) & 4.1 \\
\hline \multirow[t]{5}{*}{ Others } & Amylase (U/L) & 23 \\
\hline & Lipase (U/L) & 12 \\
\hline & D dimer (mg/dl) & 0.4 \\
\hline & Ferritin $(\mu \mathrm{g} / \mathrm{L})$ & 45 \\
\hline & CRP (mg/l) & 1.5 \\
\hline
\end{tabular}

$C B C$ complete blood picture, $H B$ hemoglobin, $W B C s$ white blood cells, $M C V$ mean corpuscular volume, $M C H C$ mean corpuscular volume concentration, $R D W$ red cell width, $P T$ prothrombin concentration, INR international normalized ratio, AST aspartate transaminase, ALT alanine transaminase, ALP alkaline phosphatase, GGT gamma glutamyl transferee, CRP C-reactive protein stones that just were waiting to jump out of the CBD (supplementary video 1 ).

Then, an extractor balloon was inserted into the papillary orifice, which was able to retrieve a large number of resembling intensely black stones. A plastic biliary stent $10 \times 10$ French has been deployed, and then, the procedure was terminated, and the patient was assigned for a follow-up ERCP 1 month later.

\section{Discussion}

Cholelithiasis is a commonly encountered clinical disorder in both emergency and out-patient clinics [7]. The prevalence of CBD stones coexisting with gallstones is estimated to range from 8 to $15 \%$ before the age of 60 years to up to $60 \%$ in the older population [8]. Also, compared to male patients, females are twice as likely to have coexisting CBD stones [9].

Abdominal ultrasound can accurately show gall bladder stones but has poor sensitivity in the diagnosis of choledocholithiasis [10]. However, sonographic detection of multiple small gall bladder calculi can be predictive for simultaneous small CBD stones [10]. Such sonographic predictive value of choledocholithiasis is 4 -fold higher with multiple calculi less than $5 \mathrm{~mm}$ in opposing to larger and solitary stones [11]. Of note, sonographic detection of dilated CBD more than $7 \mathrm{~mm}$ can be highly indicative of biliary obstruction either calcular or noncalcular [12]. The ultrasound findings in the present case were in support of both presence of CBD stones mostly small ones and biliary obstruction.

Normal serum levels of liver function tests have shown to have a negative predictive value (NPV) for complicated CBD stones as high as $98 \%$ and people with normal liver function tests would not be subjects for further investigations [13]. In contrary to sonographic findings, in this case, normal liver testing along with clinical data were strongly arguing against complicated CBD stones and deterring performing further intervention. However, it was theorized that a slow process of marked dilatation of the CBD may serve as a blunting reservoir for the elevation of liver testing parameters and this might explain the lack of complications in this case despite ERC documentation of such a quantity of small-sized choledocholithiasis [14]. Also, such significant CBD dilatation with the migration of innumerable stones from the gall bladder may induce some proximal pressure effect and consequent mild dilatation of the proximal biliary channels.

Likewise, in the present case, such a small size of the stones might be associated with spontaneous peaceful passage of numerous stones and prolonged asymptomatic history in this case.

ERCP is a positioned technique in the management of CBD stones and has been considered the gold standard in the diagnosis and treatment of suspected CBD stones 


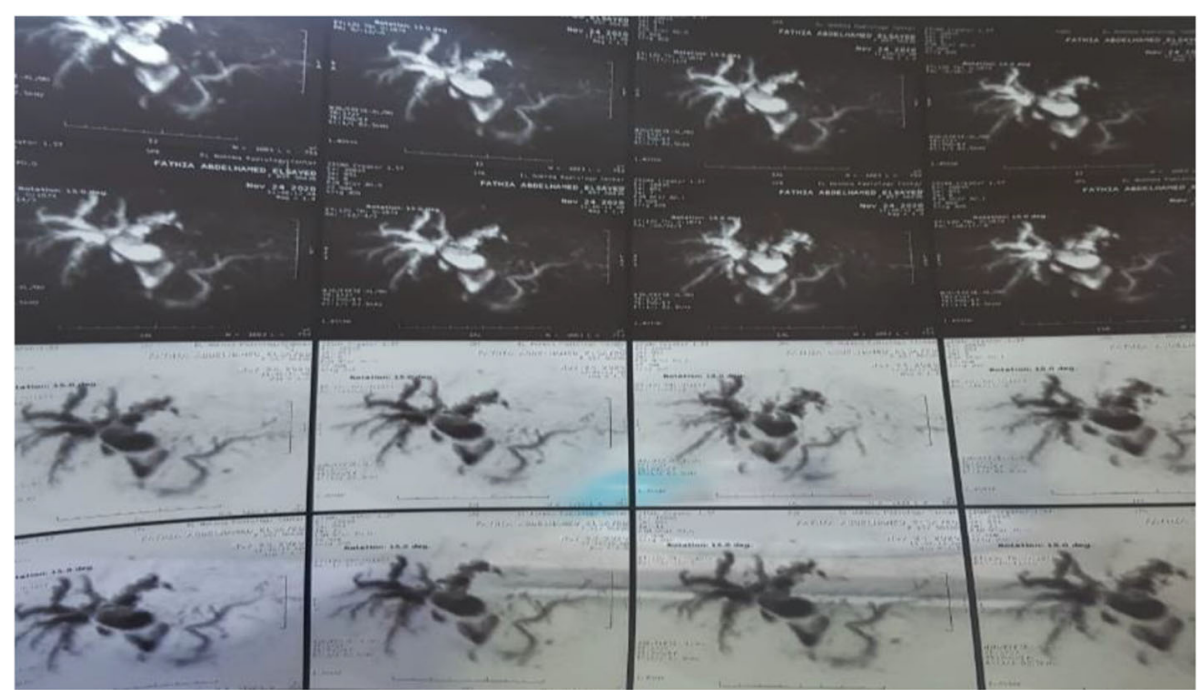

Fig. 1 MRCP showing dilated CBD and proximal biliary channels with, neither filling defects nor stricturing was evident

[3]. Reportedly, magnetic resonance cholangiography (MRC) can identify up to $91 \%$ of biliary stones, but small calculi less than $5 \mathrm{~mm}$ can be shown in only $71 \%$ of cases [15]. In this case, the diagnosis of CBD stones has been achieved by ERCP while MRCP has failed to show any filling defects.

According to the American Society for Gastrointestinal Endoscopy (ASGE) practice guidelines to assign risk stratification of choledocholithiasis, dilated CBD to $6 \mathrm{~mm}$ and more (11 $\mathrm{mm}$ in our case) was considered a strong predictor of CBD stones [16]. It is generally recommended that CBD stones have to be removed even in asymptomatic individuals because of the serious sequelae and associated mortality [17]. Therefore, ERCP has been the favored and attentive management in this case.

The last point to be explained in this elderly patient who expressed disinterest in doing further laboratory investigations is the pigment black stones in absence of overt hemolytic disorder, the non-cirrhotic liver, and the in situ gall bladder. Her complete blood picture shows moderate anemia, low mean corpuscular volume (MCV), increased mean corpuscular volume concentration (MCHC), and mildly raised red cell width (RDW). All these parameters combined with the late-onset black choledocholithiasis can be explained in view of an occult hemolytic disorder intermittently causing repeated

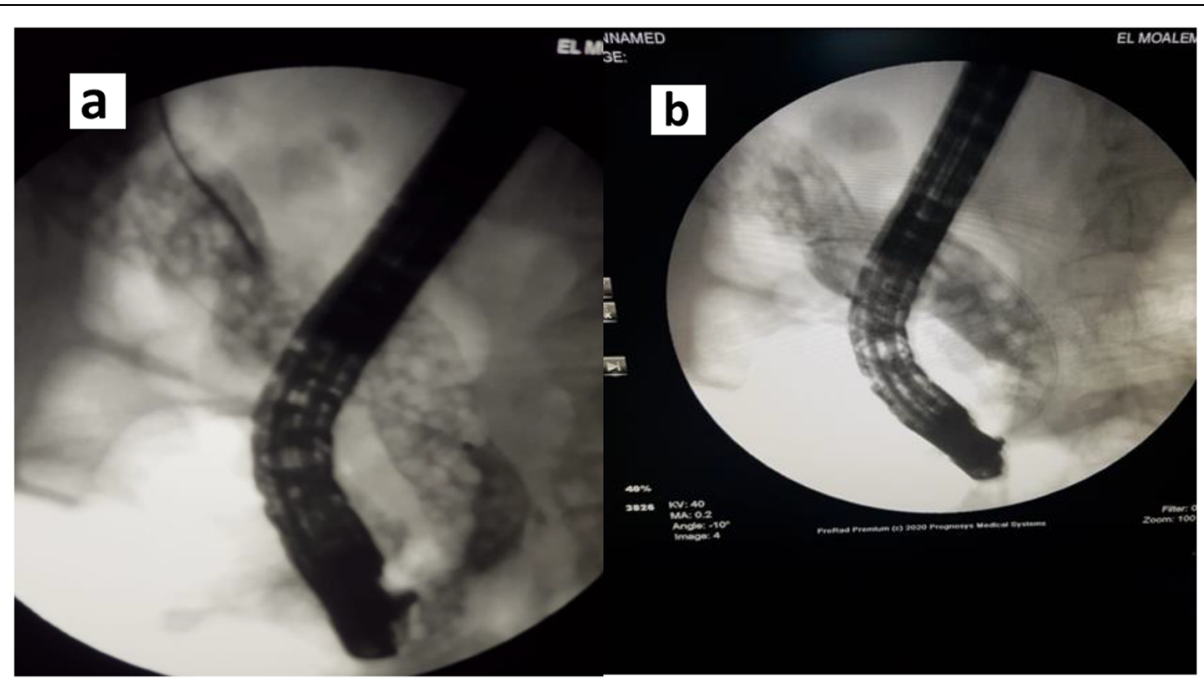

Fig. 2 a, b Endoscopic retrograde cholangiogram demonstrated markedly dilated CBD with innumerable filling defects corresponding to small stones 
undiagnosed hemolytic attacks and in the long term inducing these intensely black pigment stones in our elderly patient $[18,19]$. As her sonography showed a normal-sized spleen, the possibility that a trait of either sickle cell disease or beta thalassemia can be dominating [18]. Certainly, a combined iron deficiency anemia can be suggested due to poor appetite or bad iron utilization and may engage in the development of such a picture of moderate rather than mild anemia.

As evidently clear in this case, the lack of bacterial cholangitis is the typical setting to form black rather than brown pigment stones [2]. Additionally, a gall bladder hypo-contractility in such an elderly patient could represent a synergistic pathophysiological background for her non-overt hemolysis-related black calculi [20].

\section{Conclusion}

Choledocholithiasis can atypically present in the aged population. Paucity of the diagnostic data in such a population should not deter further intervention.

\section{Abbreviations}

CBD: Common bile duct; ERCP: Endoscopic retrograde

cholangiopancreatography; MRC: Magnetic resonance cholangiography

\section{Supplementary Information}

The online version contains supplementary material available at https://doi. org/10.1186/s43066-021-00114-7.

Additional file 1. Video illustrating the retrieval of large number of small black stones by ERCP. Description of data: video.

\section{Acknowledgements}

All authors are indebted to Professor Omkolsoum Alhaddad for her great efforts in fulfilling this work.

\section{Authors' contributions}

EO analyzed and interpreted the patient data and was a major contributor in writing the manuscript. EM helped in revising the manuscript. $\mathrm{HO}$ analyzed and interpreted the patient data regarding the hematological disease. KA performed the endoscopic intervention. EH helped in case analysis. All authors read and approved the final manuscript.

\section{Funding}

No funding resources.

Availability of data and materials

All the data is available in the manuscript.

\section{Declarations}

\section{Ethics approval and consent to participate}

The case was written after the consent of the ethical committee of National Liver Institute, Menoufia University

\section{Consent for publication}

Written informed consent was obtained from the patient for publication of this case report and accompanying images.

\section{Competing interests}

All authors declare that they have no competing interests.

\section{Author details}

'Department of Hepatology and Gastroenterology, National Liver Institute, Menoufia University, Shebeen El-Koom 32511, Egypt. ${ }^{2}$ Department of Clinical Pathology, National Liver Institute, Menoufia University, Shebeen El-Koom 32511, Egypt.

Received: 3 February 2021 Accepted: 18 May 2021

Published online: 08 June 2021

\section{References}

1. Murphy MC, Gibney B, Gillespie C, Hynes J, Bolster F (2020) Gallstones top to toe: what the radiologist needs to know. Insights Imaging 11:1311-1313

2. Trotman BW (1991) Pigment gallstone disease. Gastroenterol Clin North Am. 20(1):111-126. https://doi.org/10.1016/S0889-8553(21)00536-7

3. Costi R, Gnocchi A, Di Mario F, Sarli L (2014) Diagnosis and management of choledocholithiasis in the golden age of imaging, endoscopy and laparoscopy. World J Gastroenterol. 20(37):13382-13401. https://doi.org/10.3 748/wjg.v20.i37.13382

4. Corfield AP, Cooper MJ, Williamson RCN (1985) Acute pancreatitis: a lethal disease of increasing incidence. Gut 26(7):724-729. https://doi.org/10.1136/ gut.26.7.724

5. Toh SKC, Phillips S, Johnson CD (2000) A prospective audit against national standards of the presentation and management of acute pancreatitis in the south of England. Gut 46(2):239-243. https://doi.org/10.1136/gut.46.2.239

6. Salek J, Livote E, Sideridis K, Bank S (2009) Analysis of risk factors predictive of early mortality and urgent ERCP in acute cholangitis. J Clin Gastroenterol 43(2):171-175. https://doi.org/10.1097/MCG.0b013e318157c62c

7. Tanaja J, Lopez RA, Meer JM. Cholelithiasis. [Updated 2020 Dec 7]. In: StatPearls. Treasure Island: StatPearls Publishing; 2020 Jan-.Available from: https://www.ncbi.n/m.nih.gov/books/NBK470440/

8. Bergman S, Sourial N, Vedel I, Hanna WC, Fraser SA, Newman D, Bilek AJ, Galatas C, Marek JE, Monette J (2011) Gallstone disease in the elderly: are older patients managed differently? Surg Endosc. 25(1):55-61. https://doi. org/10.1007/s00464-010-1128-5

9. Reddy S, Jagtap N, Kalapala R, Ramchandani M, Lakhtakia S, Basha J, Nabi Z, Karyampudi A, Chavan R, Tandan M, Gupta R, Reddy DN (2021) Choledocholithiasis in acute calculous cholecystitis: guidelines and beyond. Ann Gastroenterol 34:1-6

10. Costi R, Sarli L, Caruso G, lusco D, Gobbi S, Violi V, Roncoroni L (2002) Preoperative ultrasonographic assessment of the number and size of gallbladder stones: is it a useful predictor of asymptomatic choledochal lithiasis? J Ultrasound Med. 21(9):971-976. https://doi.org/10.7863/jum.2 002.21.9.971

11. Alkarboly T, Fatih S, Hussein H, Ali T, Faraj H (2016) The accuracy of transabdominal ultrasound in detection of the common bile duct stone as compared to endoscopic retrograde cholangiopancreatography (with Literature Review). Open J Gastroenterol 6(10):275-299. https://doi.org/1 0.4236/ojgas.2016.610032

12. Essam M, Salama M, Abd Elkader H, Hussein A (2018) Role of MRCP in the assessment of patients undergoing cholecystectomy. Egypt J Hospital Med 72(2):3879-3885

13. Isherwood J, Garcea G, Williams R, Metcalfe M, Dennison AR (2014) Serology and ultrasound for diagnosis of choledocholithiasis. Ann R Coll Surg Engl. 96(3):224-228. https://doi.org/10.1308/003588414X13814021678033

14. McNicoll CF, Pastorino A, Faroog U, et al. Choledocholithiasis. [Updated 2020 Jun 18]. In: StatPearls [Internet]. Treasure Island (FL): StatPearls Publishing; 2020 Jan-. Available from: https://www.ncbi.nlm.nih.gov/books/ NBK441961/

15. Mari M, Calvo M, Bujanda M, Calderón A, Heras I, Cabriada J, Bernal A, Orive A, Capelastegi A (2002) Role of Magnetic Resonance Cholangiopancreatography in Patients With Suspected Choledocholithiasis. Mayo Clinic's Proc 77(5):403-502

16. Singhvi G, Ampara R, Baum J, Gumaste V (2016) ASGE guidelines result in cost-saving in the management of choledocholithiasis. Ann Gastroenterol. 29(1):85-90

17. Williams EJ, Green J, Beckingham I, Parks R, Martin D (2008 Jul) Lombard M; British Society of Gastroenterology. Guidelines on the management of common bile duct stones (CBDS). Gut. 57(7):1004-1021. https://doi.org/1 $0.1136 /$ gut.2007.121657

18. Kotila T (2016) R: Sickle Cell Trait: A Benign State? Acta Haematol 136(3): 147-151. https://doi.org/10.1159/000446526 
19. Di Francesco V, Zamboni M, Dioli A, Zoico E, Mazzali G, Omizzolo F, Bissoli L, Solerte SB, Benini L, Bosello O (2005) Delayed postprandial gastric emptying and impaired gallbladder contraction together with elevated cholecystokinin and peptide YY serum levels sustain satiety and inhibit hunger in healthy elderly persons. J Gerontol: Series 60(12):1581-1585. https://doi.org/10.1093/gerona/60.12.1581

\section{Publisher's Note}

Springer Nature remains neutral with regard to jurisdictional claims in published maps and institutional affiliations.

Submit your manuscript to a SpringerOpen ${ }^{\circ}$ journal and benefit from:

- Convenient online submission

- Rigorous peer review

- Open access: articles freely available online

- High visibility within the field

- Retaining the copyright to your article

Submit your next manuscript at $\boldsymbol{\wedge}$ springeropen.com 